\title{
INJURIES OF THE ATLAS AND AXIS
}

\author{
B. J. S. Grogono, London, England
}

Formerly Orthopaedic Registrar, Addenbrooke's Hospital, Cambridge

This paper is presented to show some of the problems encountered in the diagnosis and management of injuries of the upper two cervical vertebrae. It is based on a review of all such injuries treated at Addenbrooke's Hospital, Cambridge, in the last ten years.

\section{ANATOMY}

The atlanto-axial articulation is unique in allowing a wide range of rotation, for which the shape of the articular surfaces and their ligaments are specially adapted. The lateral articular surfaces face downwards and forwards, so that rotation of the atlas upon the axis is accompanied by slight vertical descent of the head. The cruciate ligament, composed of transverse and vertical bands, is chiefly responsible for maintaining the odontoid process

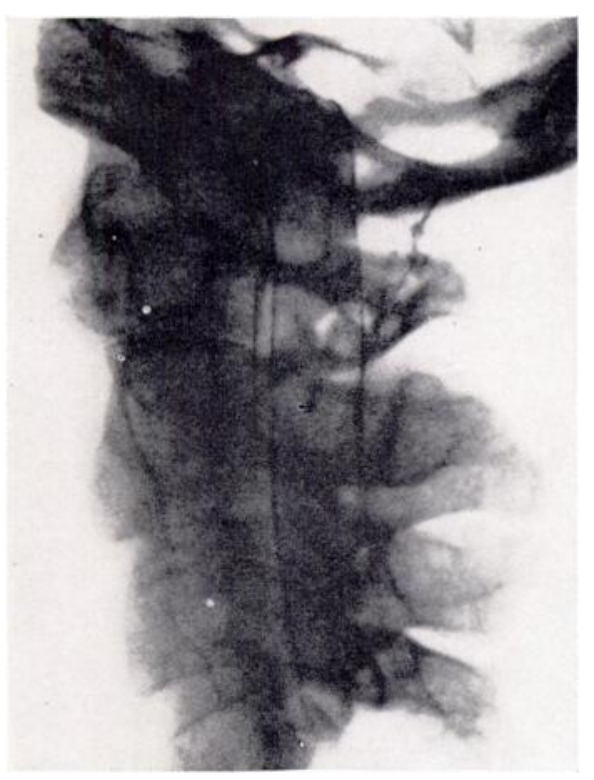

FIG. 1

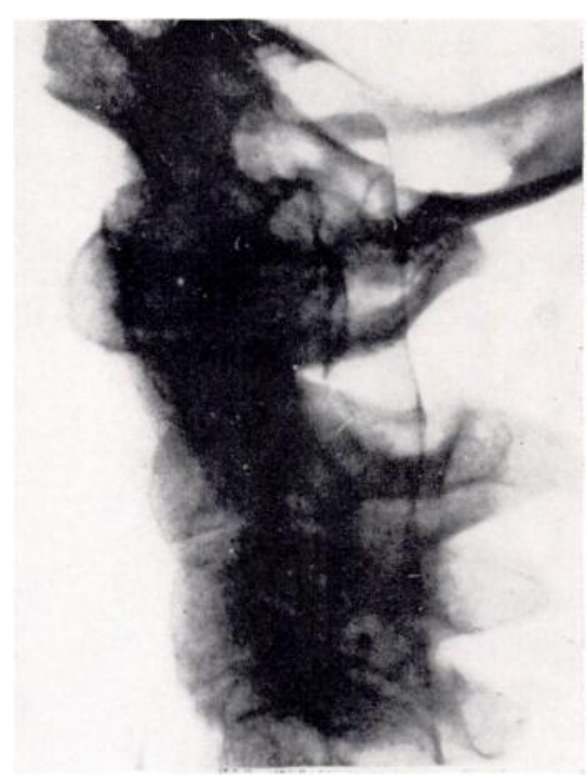

FIG. 2

Radiographs of dissected specimen of upper cervical spine. Dura outlined with barium sulphate.

Figure 1-Normal. Figure 2-After forcible anterior displacement. The odontoid process caused indentation of the front of the spina! cord.

in its correct position. The alar and accessory atlanto-axial ligaments help to limit extremes of rotation, and because of the oblique direction of the lateral atlanto-axial joint surfaces this action is delayed by flexion of the head. The central articulation between the odontoid process and the atlas is a synovial joint. Its ligaments are covered by a strong band, the membrana tectoria. Posteriorly the atlas and axis are connected by a ligament in series with the ligamenta flava; it is pierced by the second cervical nerve, which is thus sometimes involved in injuries of the atlas (Jefferson 1920). The spinal cord is suspended from each side of the vertebral column by the denticulate ligaments. It is in close relationship with the back of the odontoid and with the arch of the atlas.

In a fresh necropsy specimen from an elderly subject the transverse and accessory 
ligaments were divided. It was found that considerable force was required to cause displacement of the atlas (Figs. 1 and 2 ). It must therefore be presumed that there is laxity of all the ligaments between the atlas and axis in cases of spontaneous dislocation.

Development-The atlas is ossified from three primary centres, one for each lateral mass and

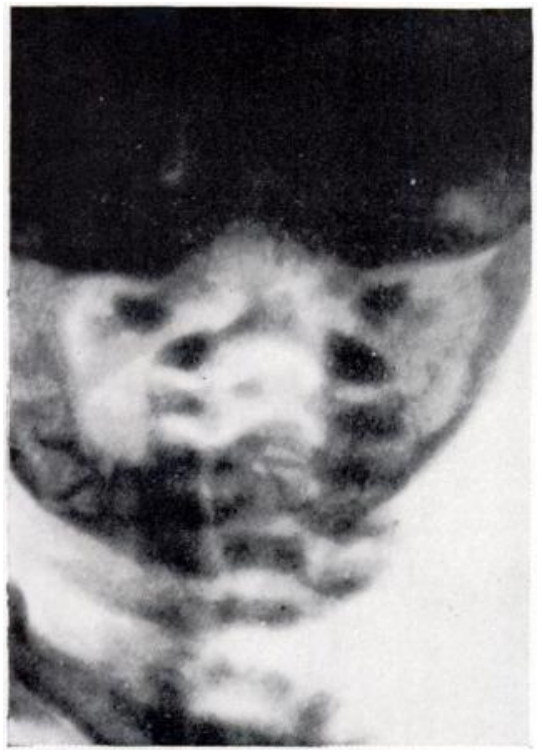

FIG. 3

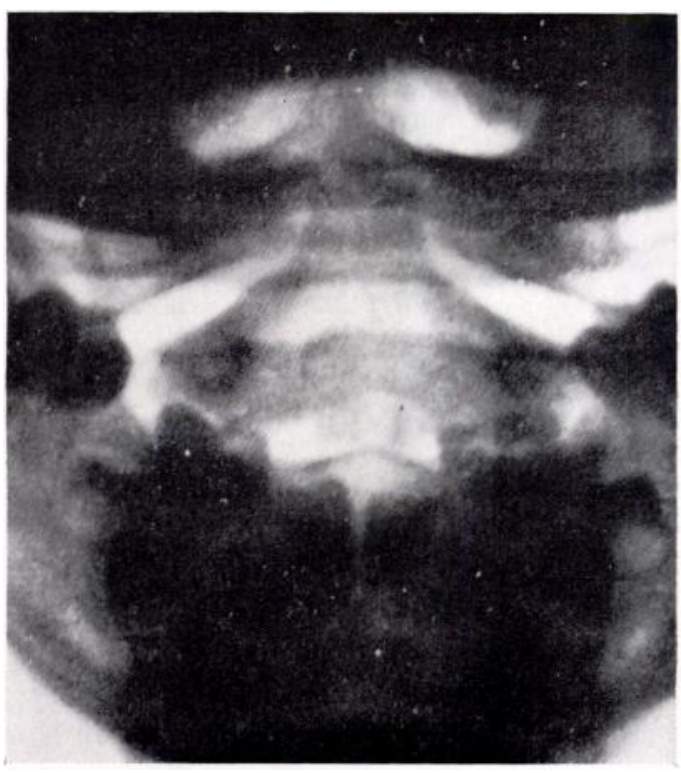

FIG. 4

Figure 3-Radiograph showing centres of ossification present at eleven days. Figure 4-Radiograph showing centres of ossification present at five and a half years.

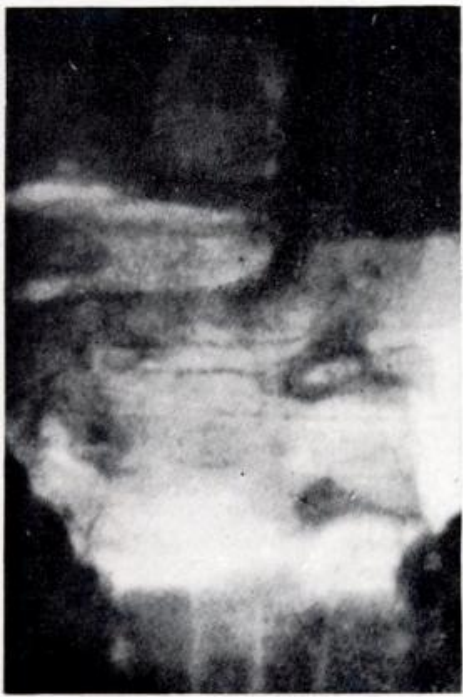

FIG. 5

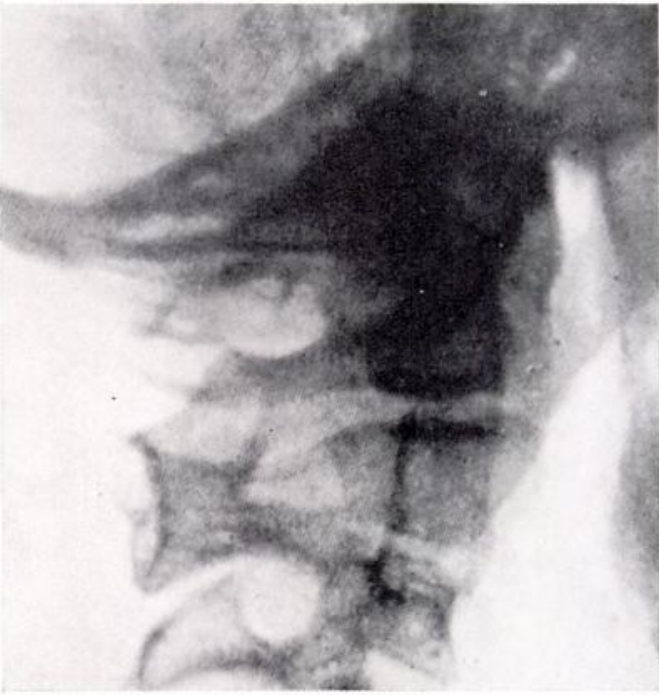

Fig. 6

Congenital abnormalities. Figure 5-Absence of the anterior arch of the atlas. Figure 6-Fusion of the upper three cervical vertebrae.

one for the anterior arch. The axis is developed in seven centres. The five primary centres comprise two for the vertebral arch, one for the body, and two lateral centres from which the base of the odontoid is formed. The peg of the odontoid is developed from secondary centres which unite with the base of the odontoid process at the twelfth year. 
At birth the odontoid is represented only by its lower two centres of ossification (Fig. 3). Figure 4 shows the appearances in a child of five and a half.

\section{RADIOGRAPHIC FXAMINATION}

The routine projections used in this study are the antero-posterior and lateral. The antero-posterior radiograph is best taken through the open mouth. Plain radiographs do not always exclude the possibility of subluxation between the atlas and axis (Swanberg 1919). Jackson (1950) radiographed fifty normal adults and fifty children and measured in each the distance between the anterior arch of atlas and the odontoid process. In adults the average distance was $2 \cdot 5$ millimetres but in children it varied up to $4 \cdot 5$ millimetres.

In the interpretation of the radiographs the possibility of congenital abnormalities should be borne in mind. There may be failure of normal fusion of ossific centres, or there may be abnormal fusion, as between the atlas and the occiput or between the atlas and axis (Figs. 5 and 6 ). The variations that occur may be compared with those that affect the lumbo-sarcal region. Thus the term " occipitalisation of the atlas " has been coined and the idea of " cervical axial spondylolisthesis " (Kahn and Yglesias 1935) as a factor predisposing to injury has been presented. Special radiographic techniques-tomography, stereoscopic views, and the use of contrast media-may be necessary in investigating these cases.

\section{CLASSIFICATION OF INJURIES OF THE ATLAS AND AXIS}

The following classification is based on those of Corner (1907), Sullivan (1949), and Cone and Turner (1937).

\section{Fractures without dislocation.}

Atlas.

Axis.

\section{Dislocation without fracture.}

Fracture-dislocations.

Forward (unilateral or bilateral).

Backward.

\section{ISOLATED FRACTURE OF THE ATLAS}

The mechanism of this injury was described by Jefferson (1920), who reviewed twenty-one cases together with a further twenty-five cases complicated by other injuries of the cervical

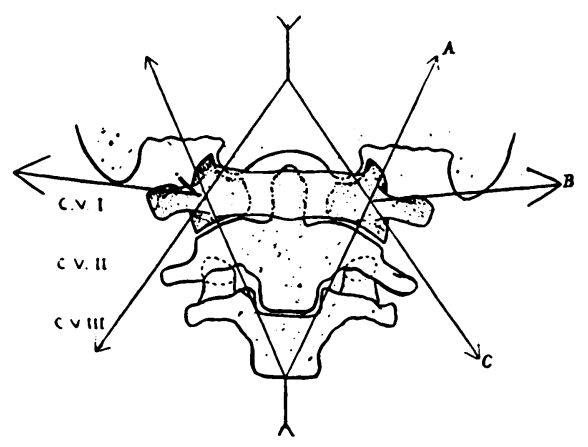

FIG. 7

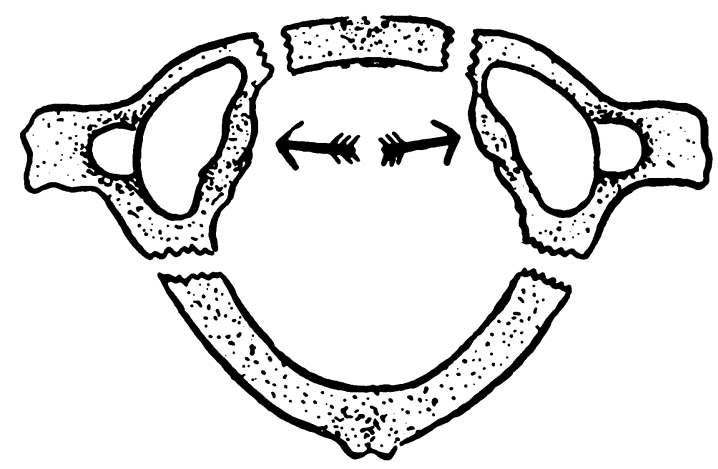

FIG. 8

Figure 7-Jefferson's diagram illustrating the disrupting forces acting upon the atlas. Figure 8-Atlas viewed from above to show the result of "spreading," the bony arch yielding at its weak points (Jefferson).

spine. According to Jefferson, isolated fractures of the atlas usually result from indirect violence from impact of the head on the ground. The violence is transmitted through the occipital condyles to the atlas and meets opposing forces transmitted by the spine to the axis vertebra. In consequence of the sloping articular surfaces of the lateral atlanto-axial

vol. $36 \mathrm{~B}$, No. 3 , AUgust 1954 
joints there is a disrupting tension on the atlas ring (Fig. 7). The weakest points of the ring are in the anterior and posterior arches (Fig. 8). Fracture of the thick lateral mass occurs only when the head is flexed to one side at the time of the injury, so that considerable force is transmitted through it. In Jefferson's series the fracture involved the posterior arch in twenty-five cases, the anterior arch in seventeen, and the lateral mass in seven. The spinal

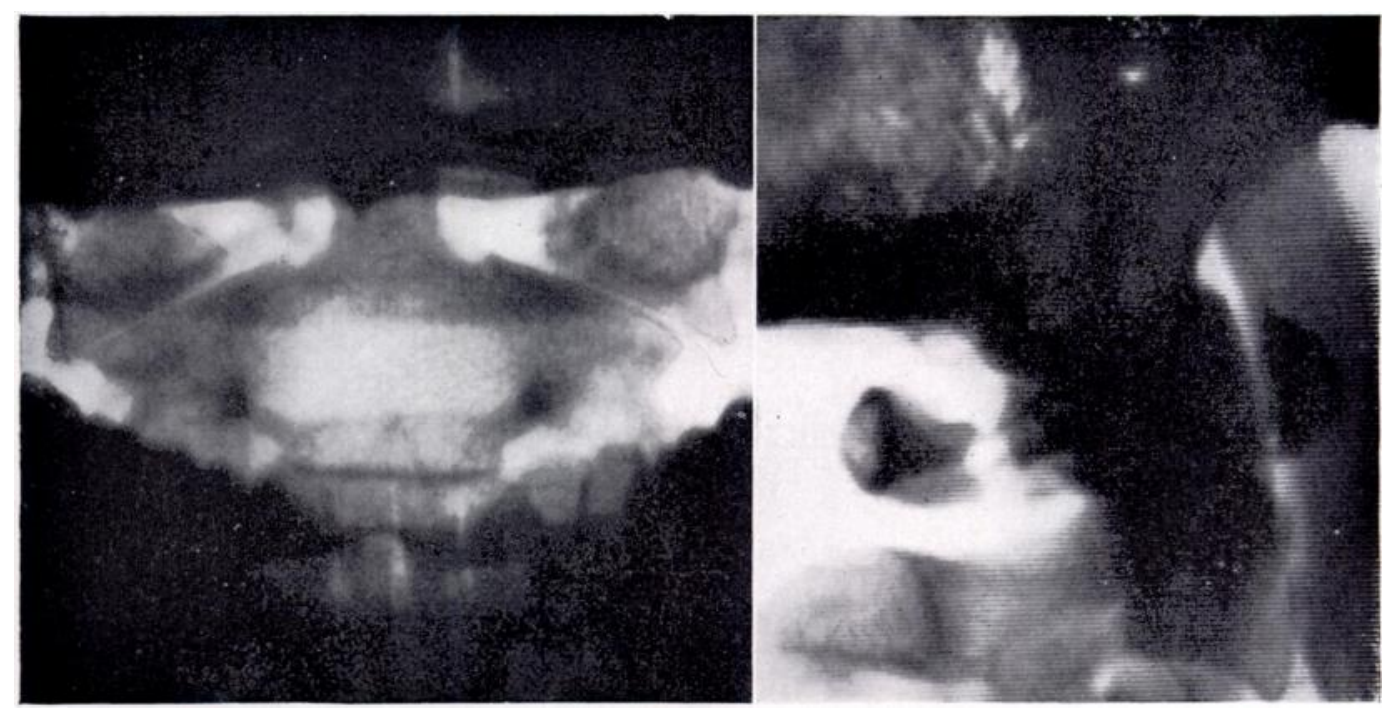

FIg. 9

Case 1-Isolated fracture of the atlas. Note in the antero-posterior view the displacement of the articular facets.

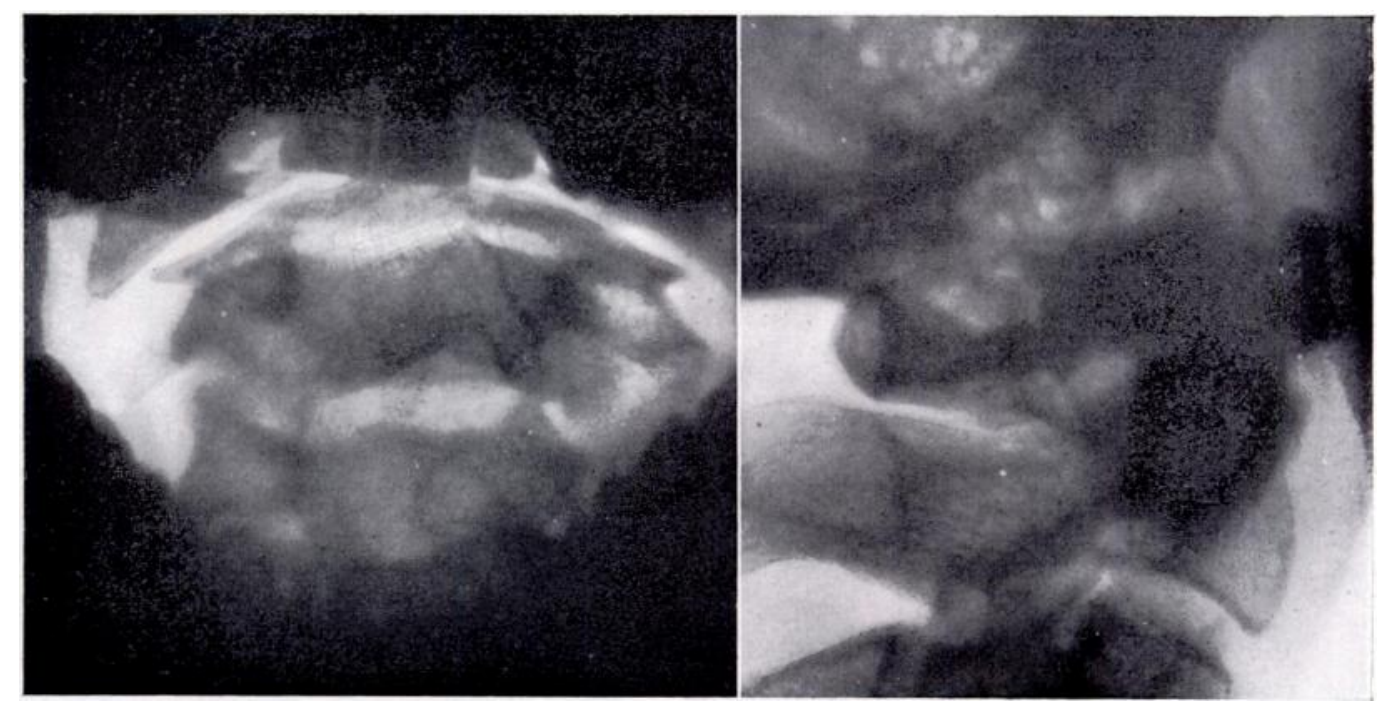

FIG. 10

Case 1-Three months after injury. The displacement of the facets remains but the laminae have united.

cord was injured in nineteen of the forty-six cases; but in most of these the fracture of the atlas was associated with other injuries of the cervical spinal column. Injury to the greater occipital nerve is to be expected with fractures of the posterior arch.

CASE REPORT

Case 1-A man of twenty-one collided head-on with another player during a game of rugby football. Despite pain in his neck he continued playing. He walked to the hospital holding his 
head with his hands. Examination showed local tenderness over the upper cervical spine and limitation of rotation. No neurological abnormality was detected in the central nervous system. Radiographs showed fractures of the anterior and posterior arches of the atlas (Fig. 9). After two days' rest in bed a plaster collar was applied and a week later he was allowed up. The plaster was retained for three months. Radiographs after its removal showed that the fractures were uniting, but the atlas ring remained enlarged (Fig. 10).

\section{ISOLATED FRAGTURE OF THE ATLAS}

No case of isolated fracture of the axis was encountered in this series.

\section{SPONTANEOUS DISLOCATION OF THE ATLAS AND AXIS}

Sullivan (1949) reviewed fifty-two cases from the literature and reported four further cases. He recognised anterior displacement on one or both sides, and posterior displacement. The average age of the patients was thirteen years. Most cases occurred in association with inflammatory lesions in the neck, including rheumatic fever, cervical gland infection, pharyngitis, retropharyngeal abscess, influenza, rheumatoid arthritis, and tonsillectomy. A case of voluntary displacement by which the owner gained a livelihood has been described (Brav 1936). A case is also recorded of dislocation in a newborn infant after difficult delivery (Lounavaara 1949).

Clinical features-Sullivan emphasised the clinical appearance. Unilateral anterior displacement-The head is rotated away from the affected side and tilted towards it. It is flexed forwards so that the mouth cannot always be opened to examine the naso-pharynx. The voice may have a nasal quality, from closure of the naso-pharynx by the displaced atlas bulging into the posterior wall (Hess et al. 1935). There is tenderness over the spinous processes of the atlas and axis and the axis may be rotated away from the affected side (Sudeck's sign). Compensatory cervical scoliosis may be present. Root and cord signs are infrequent. Bilateral anterior displacement-There is little rotation of the neck; the head is tilted forwards, movement in all directions is limited, and the pharyngeal bulge is prominent. Signs of compression of the spinal cord are more likely. Unilateral posterior displacement-The neck is rotated towards the affected side and extended. The spinous process of the axis is also rotated towards this side but no pharyngeal bulge is present.

\section{CASE REPORTS}

Case 2-A boy aged four years complained of neck stiffness, first noticed one week after tonsillectomy. He lay on his face with the neck flexed and the head buried in a pillow. There was pyrexia of 101 degrees Fahrenheit, with cervical adenitis, but no abnormal neurological signs were detected. Radiography showed forward subluxation of the atlas on the axis and retropharyngeal abscess (Fig. 11). The displacement was reduced and a plaster jacket applied (Fig. 12). His condition remained satisfactory for ten days, but thereafter he developed renewed pyrexia and became drowsy. Neurological examination showed an extensor plantar response on both sides, with brisk tendon reflexes and urinary incontinence. Radiographs showed that subluxation had recurred (Fig. 13). Lumbar puncture showed 300 leucocytes per cubic millimetre, but culture was sterile.

The plaster was removed, the dislocation was again reduced, and operative fusion of atlas and axis by wiring and cancellous chip grafts was undertaken. The functional result one year after operation was excellent (Fig. 14).

Case 3-A girl aged ten years complained of stiff neck which developed a week after an attack of sore throat. On examination some facial asymmetry was noticed. The head was rotated to the left and flexed to the right. The upper cervical spinous processes were prominent and tender. There were no neurological signs. Radiographs showed anterior dislocation of the atlas on the axis (Fig. 15). The dislocation was reduced but subluxation recurred on several occasions despite immobilisation in plaster.

Operation-The displacement was reduced and atlanto-axial fusion was undertaken by cancellous bone grafts with wire fixation. Radiographs three months later showed satisfactory fusion (Fig. 16).

vol. $36 \mathrm{~B}$, No. 3, AUGUSt 1954

$E_{(16)}$ 


\section{DISCUSSION}

Mechanism of displacement - The association of inflammatory processes with atlanto-axial subluxation has been recognised since 1830, when Bell described a case. Opinions differ on

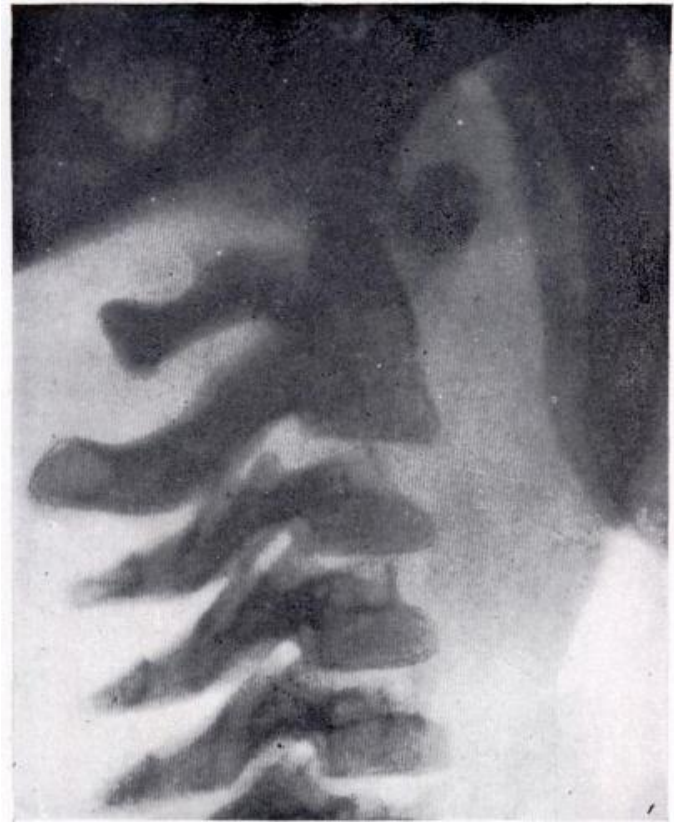

FIG. 11

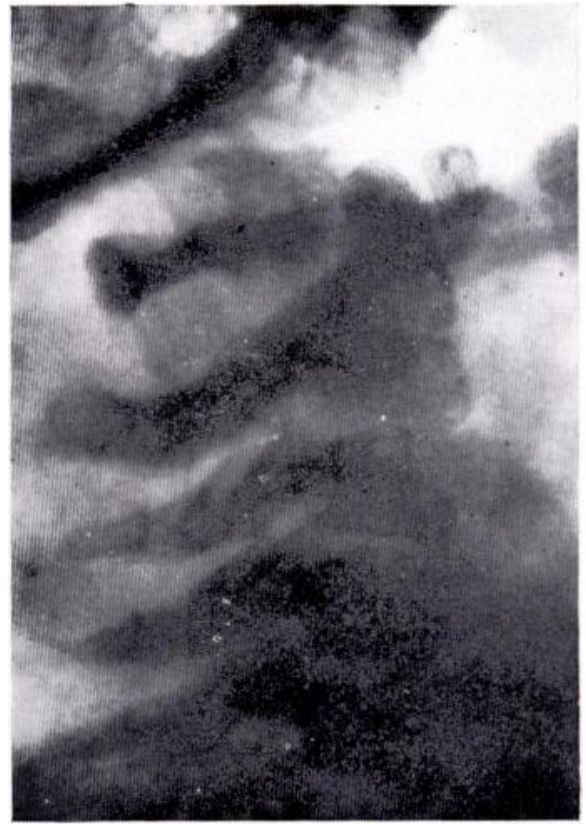

FIG. 12

Case 2. Figure 11-Spontaneous anterior subluxation of the atlas on the axis, before reduction. Figure 12-After reduction.

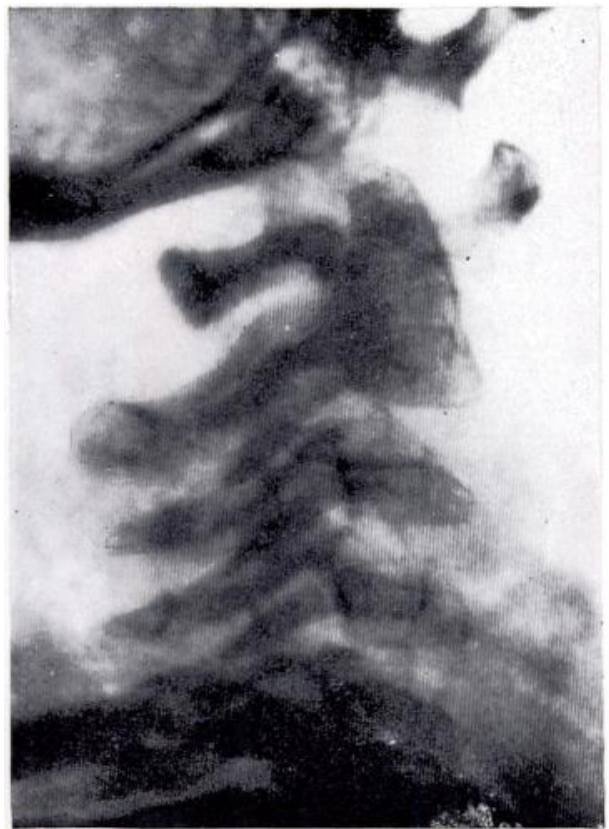

FIG. 13

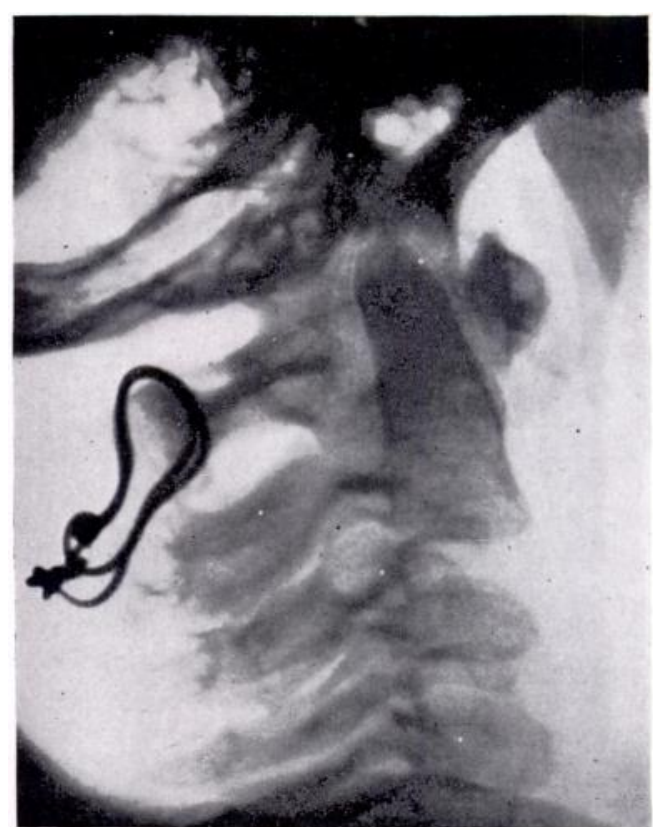

FIG. 14

Case 2. Figure 13-Recurrent subluxation in plaster. Figure 14-one year after fusion by cancellous bone chips and wire fixation.

the way in which the inflammatory changes lead to displacement. Sullivan (1949) quoted various reported hypotheses. Watson Jones (1932) noted the association of decalcification of 
the anterior arch of the atlas with the spontaneous subluxation which developed in a nine years old boy as a complication of mastoiditis. Recalcification occurred when the infection subsided. Decalcification was also found by Greig (1931) and by Leriche and Policard (1926). Other hypotheses ascribe the displacement to metatastic effusion into the joints (Wittek 1908), a combination of ligamentous laxity and muscle spasm (Hess et al. 1935), and excessive rotation of the neck under anaesthesia (Sudeck 1923). In Case 3 of this series the displacement was associated with a large retropharyngeal abscess which probably resulted from infection of a haematoma after tonsillectomy. It seems likely that considerable loosening of the transverse and accessory ligaments occurred. No decalcification of the vertebrae was seen. The case resembles that in the newborn infant described by Lounavaara (1949), in which necropsy confirmed the presence of a large retropharyngeal abscess with laxity of the transverse ligament; but in that case decalcification of the vertebrae was also noted.

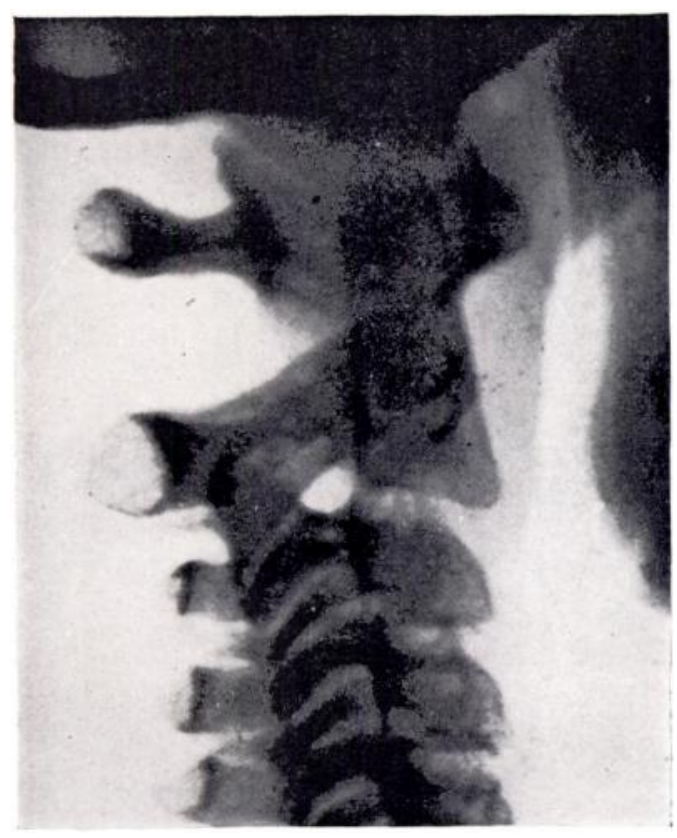

FIG. 15

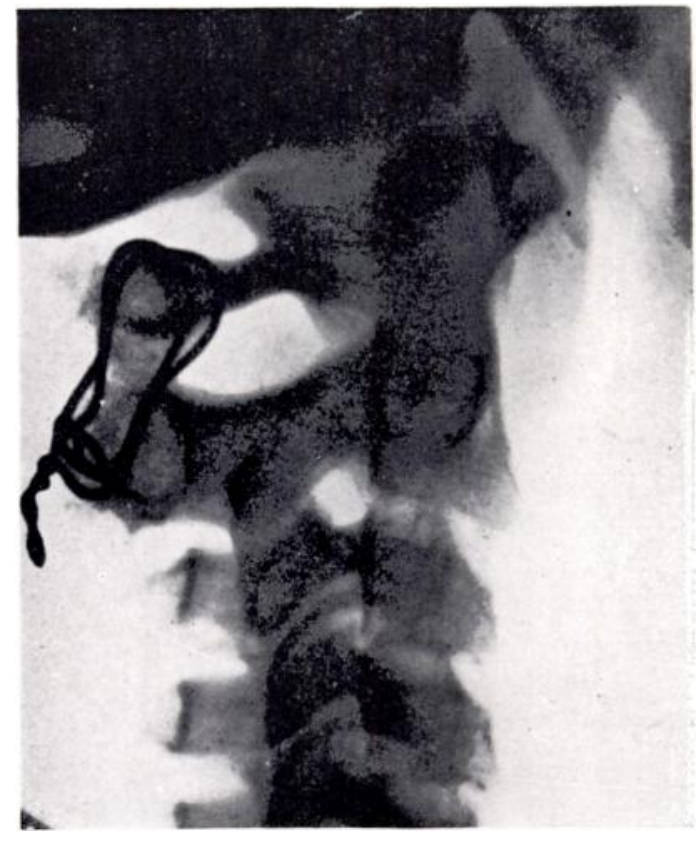

FIG. 16

Case 3. Figure 15-Spontaneous anterior atlanto-axial subluxation. Figure 16-Three months after fusion by cancellous bone chips and wire fixation.

In Case 2 there was a definite history of sore throat, but this had almost subsided before the dislocation occurred. No retropharyngeal abscess was present, and no evidence of decalcification was observed.

Diagnosis-Clinically, atlanto-axial subluxation may be suspected from a history of upper respiratory or cervical gland infection and sudden onset of a stiff neck, with the clinical signs enumerated. Radiographically the shape of the space between the anterior arch of the atlas and the odontoid process is significant. If the spinous process of the atlas is displaced forwards in relation to that of the axis, this is further evidence of a dislocation. In the antero-posterior view there may be asymmetry of the articular facets in unilateral dislocation. In doubtful cases stereoscopic views and special techniques may be required.

Treatment - The risk of atlanto-axial subluxation should be borne in mind in cases of infection in the upper cervical region, and energetic treatment with antibiotics should be begun immediately. Reduction-Walton's manoeuvre (1893) is often successful. In Case 3 reduction was obtained simply by resting the patient's shoulders on a pillow and allowing the head to extend. When traction is required a halter may be used but unless it is carefully applied it is likely to lead

vol. 36 B, No. 3 , AUGUST 1954 
to pressure sores. Skeletal traction is more satisfactory; it may be maintained for a longer period and it is more comfortable (Cone and Turner 1937).

Maintenance of reduction-It is clear from the two cases described that displacement is liable to recur. Prolonged skeletal traction would possibly have been sufficient to allow stability to be attained. Nevertheless if displacement recurs despite immobilisation in plaster operative fusion should be undertaken. Fusion should be limited to the atlas and axis; in the cases described it was obtained by wiring the posterior arch of the atlas to the spinous process of the axis with the addition of a cancellous bone graft.

\section{UNCOMPLIGATED ANTERIOR FRACTURE-DISLOGATIONS}

In fracture-dislocations there may be anterior displacement on one or both sides, or posterior displacement.

Review of previous reports-Walton (1903) gave one of the first clear descriptions of this type of injury. He noted that it was seldom fatal, and that the dislocation was usually unilateral. He described a rational method of reduction: the head was first flexed and rotated in the direction of the deformity; then it was rotated back to the mid-line.

Corner (1907) described the clinical appearance and anatomical basis of the injury. He emphasised that stability is largely dependent on the protective action of muscles. If this is absent, as in sudden unexpected violence or a strain during anaesthesia, conditions are favourable for rotatory dislocation of the atlas and fracture of the odontoid process. Corner reviewed twenty cases, of which eight were fatal. Only two of the deaths occurred soon after the accident. The most graphic account of delayed death after an injury of this type was recorded by Gibson (1885). His patient was a man of fifty-eight who had rolled down a bank and lay there all night. Being too unsteady to walk unaided, he was assisted home. His head was flexed forwards so that his chin rested on his sternum. There was a prominence of the cervical spine below the occiput. There was no paralysis, but he could not swallow. He was put to bed and steady traction was applied to the head. The dislocation reduced with a snap and crepitus was heard. He lay in bed with his head between sandbags. On the twenty-third day he sat up to eat some food, complained of abdominal pain, and dropped dead. At post-mortem there was marked separation of the spinous processes of the atlas and axis. The spinal cord was stretched tightly over the anterior surface of the spinal canal, and it was indented by the jagged edge of the body of the axis, where the odontoid had been broken. The odontoid process remained attached to the anterior arch of the atlas. There was no gross damage to the spinal cord. Other cases of delayed death were reported by Cortes (1907), Bernstein (1903) and Lambotte (1894).

Of the ten non-fatal cases recorded by Corner spinal symptoms were present only in one. Corner stated that only one patient had a fracture of the odontoid, but perhaps modern radiology would have revealed more. Corner described the characteristic position of the head in this injury. It is flexed and turned to one side. The side to which the chin is directed is that on which the transverse process of the axis is rotated backwards. The spine of the axis is rotated towards the side from which the head is bent. Sometimes this spinous process is abnormally prominent, denoting marked forward displacement of the head associated with a fracture of the odontoid process. Examination of the pharynx reveals two prominences. One is due to the forwardly displaced transverse process; the other is formed by part of the axis which has been made prominent by backward displacement of the transverse process on that side. He emphasised the increased danger if the odontoid is fractured; of the eight fatal cases coming to necropsy it was broken in six, whereas of the ten cases that recovered there was evidence of a fracture in only one.

Mixter and Osgood (1910) emphasised that redislocation and "myelitis" from late injury to the cord may occur. They described the case of a boy of one year who fell from a tree, striking his head. There was immediate pain and stiffness. Five weeks later signs were 
still present. Prominence of the cervical spines and a pharyngeal bulge suggested dislocation despite inconclusive radiographs. There was no evidence of injury to the spinal cord. The neck was manipulated by Walton's manoeuvre, and flexibility of the spine returned. The boy returned home against advice. Six months after the accident severe occipital neuralgia occurred, and a second manipulation again restored movement of the neck, and apparently reduced the dislocation. In spite of protection in a plaster collar for a month, followed by a leather Thomas's collar, symptoms returned. A lateral radiograph then showed a fracture of the odontoid process and forward dislocation of the atlas. Traction was applied to the head, and open reduction was undertaken and the posterior arch of the atlas was secured to the spinous process of the axis by silk sutures. A leather cuirass was worn for two months. Recovery was uneventful.

Cone and Turner (1937) also noted the usual absence of spinal cord symptoms after injuries in this region; they recognised the possibility of sudden death or later paralysis if

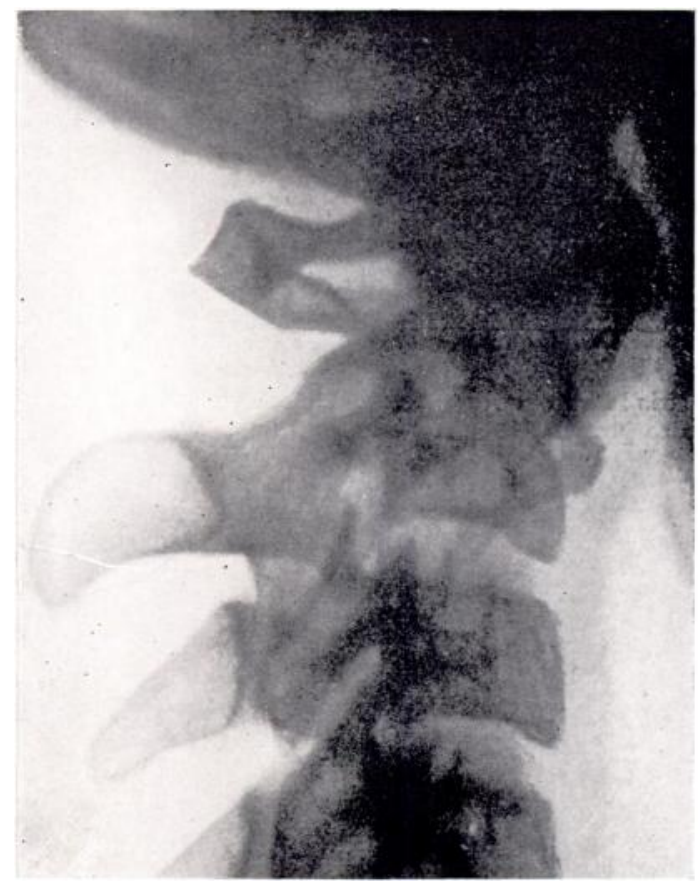

FIg. 17

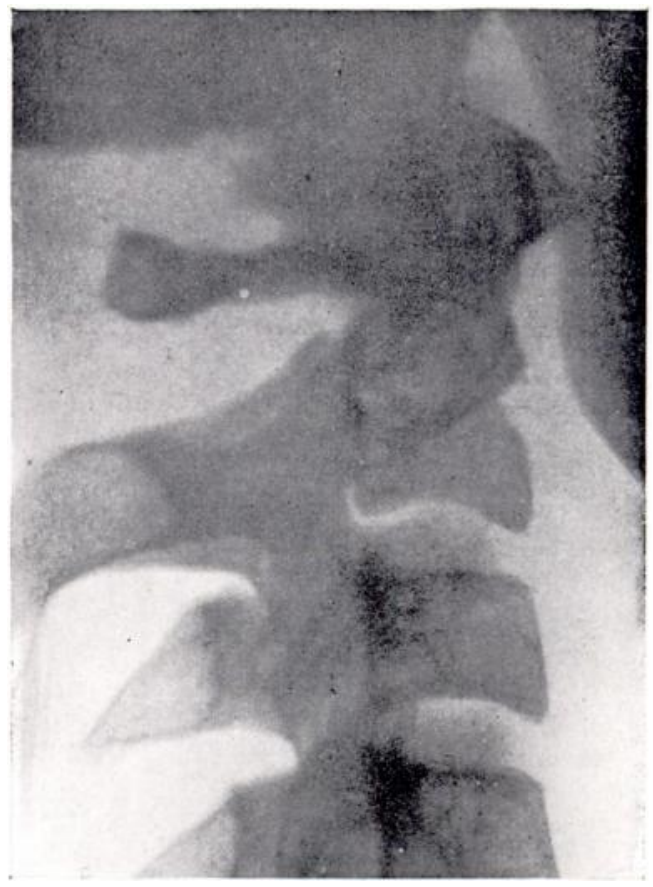

Fig. 18

Case 4. Figure 17-Fracture-dislocation of the atlas upon the axis. Figure 18-Position immediately after reduction.

the injury is not recognised and treated. They quoted the case of a doctor who dislocated his atlas while attempting a forceps delivery. Sixteen years earlier he had sustained multiple injuries in a car accident and had been unconscious for two or three days. Thereafter his neck was stiff but he continued general practice. When the forceps slipped his head was jerked forwards and he noticed sudden numbness and tingling in the fingers and weakness of the arms and legs. The neck was rigidly splinted by muscle spasm. Reflexes were present, but there was a bilateral plantar extensor response. There were no sensory changes apart from paraesthesiae of the hands. Lumbar puncture showed a complete block. Radiographs showed anterior dislocation of the atlas on the axis. Operative reduction and decompressive laminectomy were performed. The cord was found to be pressed on by the posterior arch of the atlas. Subsequent wiring and fusion of the upper six cervical vertebrae produced satisfactory recovery though considerable limitation of rotation of his neck was present.

Cone and Turner considered that skeletal traction is of great assistance in reducing these

Yol. $36 \mathrm{~B}$, No. 3, AUGUST 1954 


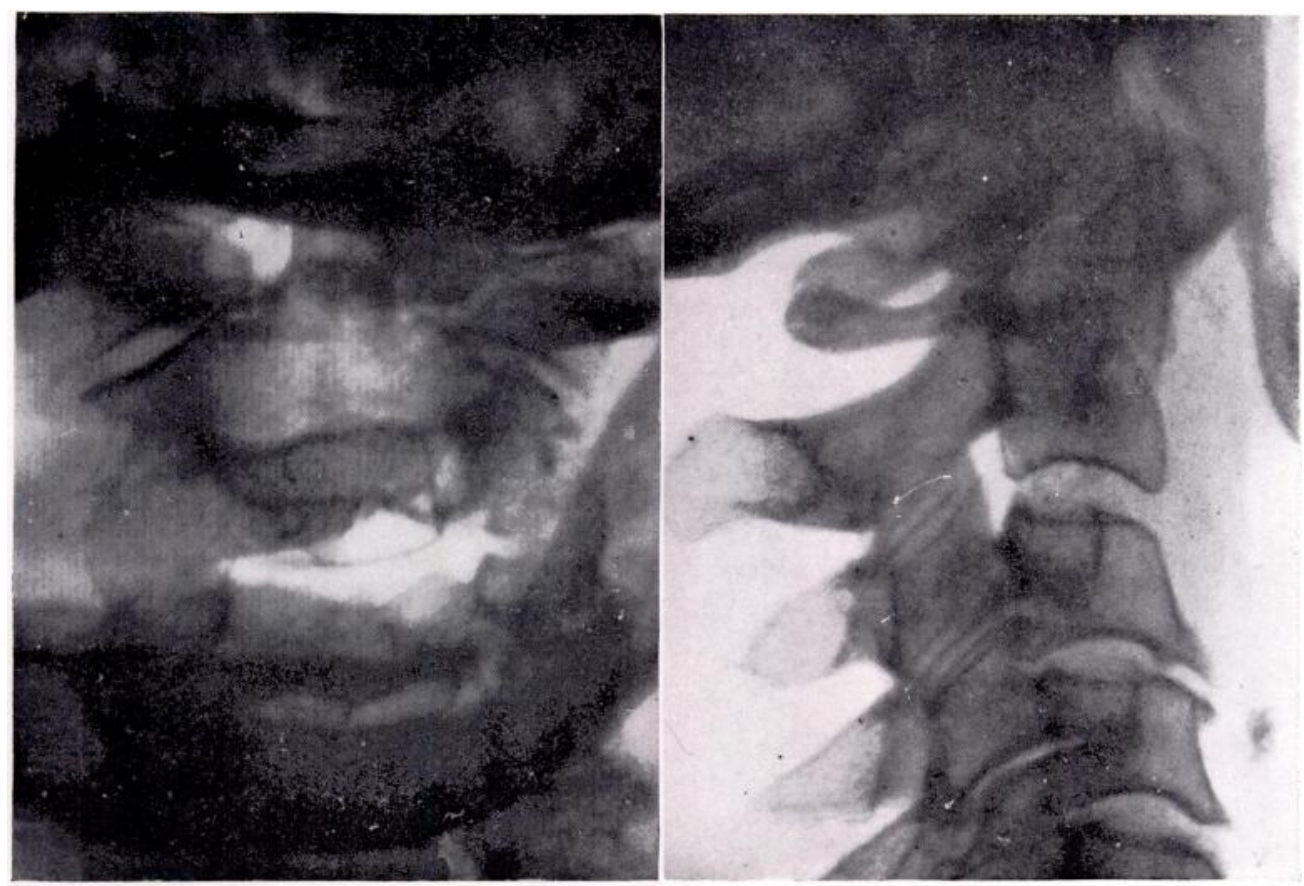

FIG. 19

Case 5-Fracture-dislocation of the atlas upon the axis in an elderly patient. Marked osteoarthritic changes were also present.
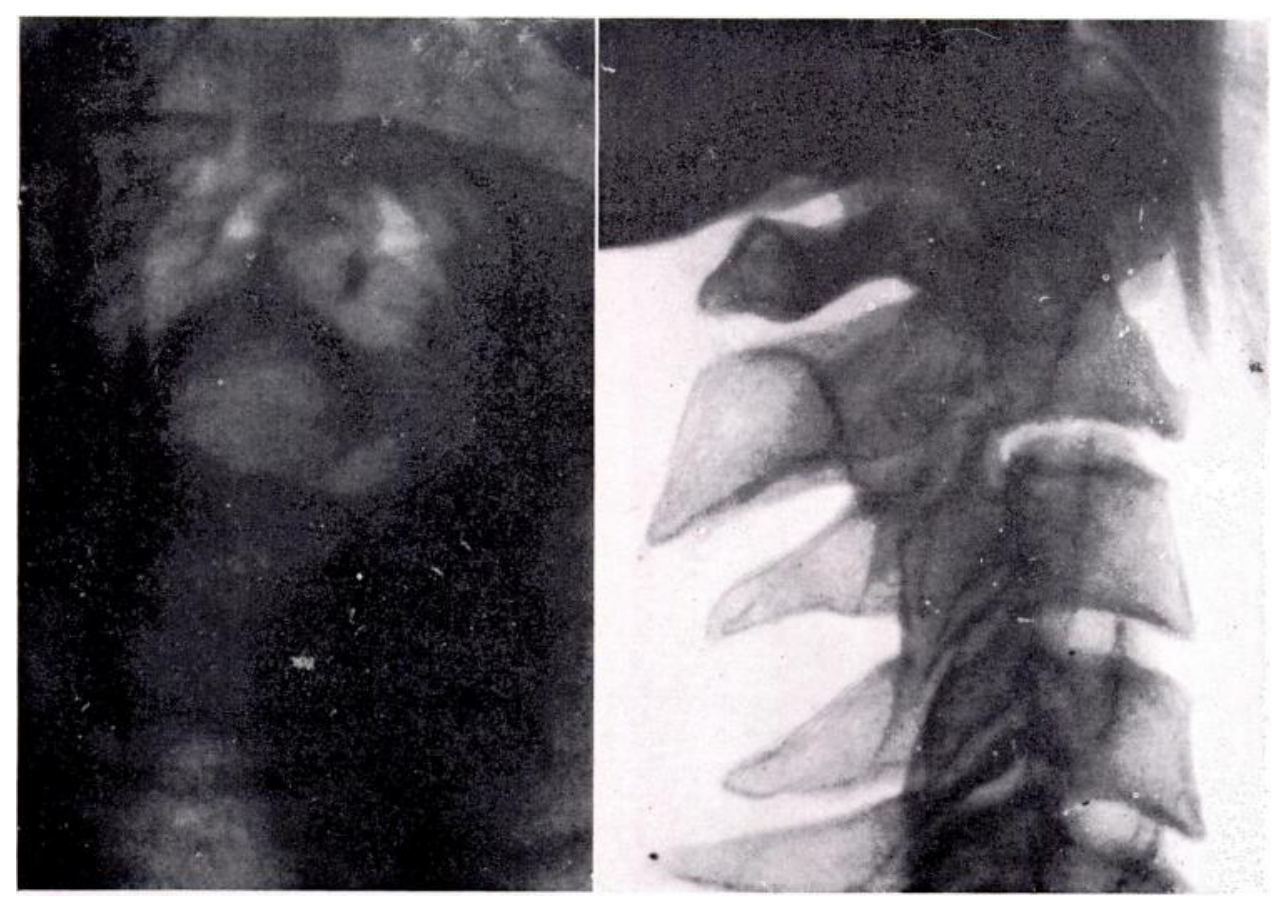

FIG. 20

Case 6-Old fracture-dislocation of the atlas upon the axis. The special projection $(l e f t)$ recommended by Cone and Turner shows an ununited fracture of the anterior arch of the atlas and displacement of the odontoid process. 
dislocations and in maintaining reduction. They advised operative fusion in cases of multiple fractures, fracture of the odontoid, recurrent displacement, or evidence of spinal cord injury:

Colsen (1949) also described fracture-dislocation of the atlas on the axis after manipulation of the neck under an anaesthetic. There were no abnormal neurological signs, but paraesthesiac of the forearms and hands were present. The dislocation was reduced by skeletal traction and the upper four cervical vertebrae were fused with satisfactory result.

\section{CASE REPORTS}

Three cases of forward dislocation of the atlas on the axis are presented to demonstrate some of the features of these injuries.

Case 4-A man of seventeen sustained a head injury while riding a motor cycle. The initial radiographs showed no fracture of the skull, and the atlas and axis retained their normal relationships. He was discharged from hospital after six days. Nine weeks later he was again involved in a motor cycle accident and was admitted to hospital. There was a bruise over the right zygoma, with marked tenderness over the spinous process of the second cervical vertebra. There were no neurological signs. Radiographs showed a fracture-dislocation of the atlas on the axis (Fig. 17). The displacement was reduced by manipulation (Fig. 18) and a plaster jacket was applied.

Case 5-A woman of seventy-nine fell downstairs, striking her head. There was no loss of consciousness but she noticed severe pain in the neck and chest. She was admitted to hospital four days later. There was no sensory or motor disturbance but any movement caused severe pain in the neck. There was marked limitation of all head and neck movements. Radiographs showed fracture of the odontoid process with forward subluxation of the atlas on the axis (Fig. 19). A plaster collar was applied. This had to be removed two days later because she would not tolerate it and said it was unnecessary. Her continued improvement substantiated these remarks. Three weeks later she began to sit up and was discharged after one month to a convalescent home wearing a plastic collar. One year later she wrote that she was leading an active life, had little discomfort and found the collar unnecessary.

Case 6-Another example of this type of case emphasises that complete reduction is not always necessary for a good functional result, though a prolonged convalescence may be needed before the patient returns to work. Figure 20 shows the appearance ten years after a dislocation of the atlas on the axis. This had been treated by attempted manipulative reduction and immobilisation in plaster. There were associated fractures of the third and sixth cervical vertebrae. The neck was stiff and painful for nearly two years, but eventually the patient returned to work as a roundsman. The radiograph shows an ununited fracture of the arch of the atlas. The projection is that recommended by Cone and Turner, and it is noteworthy that radiographs taken a year after the injury had failed to show these later findings.

\section{UNCOMPLICATED POSTERIOR FRACTURE-DISLOCATION}

Posterior fracture-dislocations are caused by hyperextension injuries and are less common than anterior displacements. Among those described is one by Cone and Turner (1937). A notable feature of their case was the marked hyperaesthesia in the second and third cervical dermatomes, so that the child screamed with pain by the lightest current of air striking his chin or upper neck. There were also loss of pain and temperature sensation in the right arm, and bilateral extensor plantar responses. The dislocation was reduced by skeletal traction and operative fusion was carried out.

\section{CASE REPORT}

Case 7-A woman of sixty-nine sustained a hyperextension injury of the neck in a motor accident. There was no spinal cord injury. Radiographs showed a comminuted fracture with posterior dislocation (Fig. 21). She was treated by immobilisation in plaster for eight weeks, and thereafter with a plastic collar. The functional result was satisfactory.

\section{FRACTURE-DISLOCATIONS COMPLICATED BY SPINAL CORD INJURY}

Fracture-dislocations complicated by spinal cord injury are caused by a more severe type of injury. In some cases the cord damage is due to associated fractures of other cervical vertebrae, no damage occurring at the level of the atlanto-axial articulation. Many patients with these injuries never reach a hospital alive; consequently the relative incidence of uncomplicated and complicated cases is difficult to assess. As already stated, signs of cord injury

vol. $36 \mathrm{~B}$, No. 3, AUguST 1954 


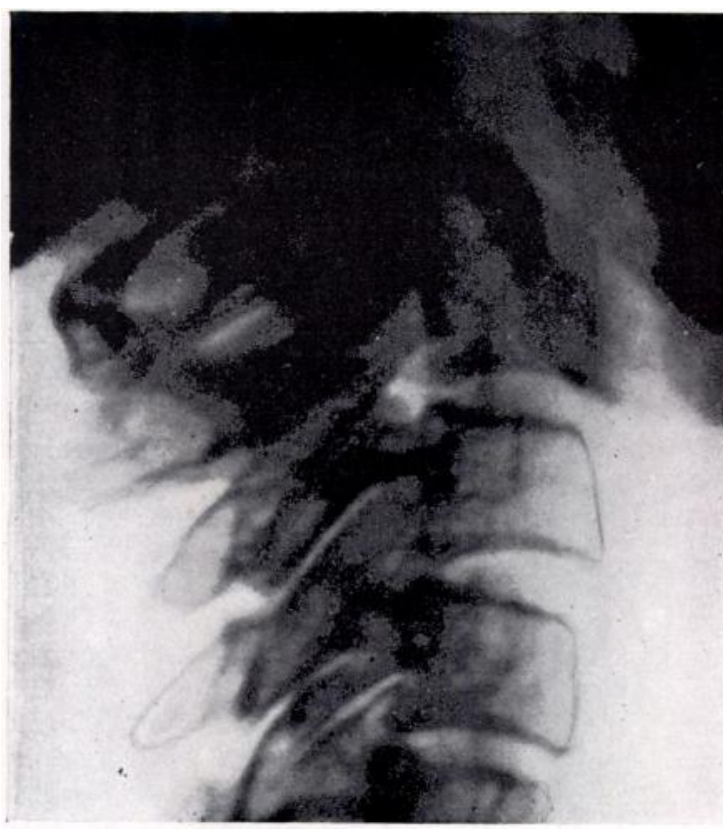

FIG. 21

Case 7-Posterior fracture-dislocation of atlas upon axis caused by a hyperextension injury. may be present immediately, or they may result from later displacement. The cord lesion may consist in compression, haematomyelia, or vascular disturbance. Recovery after reduction of the dislocation has been described (Cone and Turner) and it may also occur despite failure to reduce the displacement (Pilcher 1910).

The neurological changes have not always been closely correlated with the mechanism of a particular injury. It seems, however, that in cases of incomplete cord injury the following are the commonest features: 1) motor weakness or complete paralysis of the arms and legs; 2) exaggerated reflexes, with extensor plantar response; 3) paralysis of bladder with retention of urine; 4) impairment of pain and temperature sense (hyperextension injury, Cone and Turner 1937); 5) nerve root lesions with hyperaesthesia in the area of C.1 and 2 and occipital neuralgia; 6) paraesthesia and hyperaesthesia of hands and fingers. It appears, therefore, that the damage to the spinal cord may be most marked anteriorly. Injury to the spino-thalamic tract sometimes occurs, as in the case of a hyperextension injury described by Cone and Turner (1937). Indentation of the anterior surface of the cord was noted in a necropsy specimen by Gibson (1885), and it has been produced experimentally (Fig. 2). An exception to this generalisation is the case of the doctor described by Cone and Turner; in that case the posterior arch of the atlas was found at operation to be pressing on the spinal cord. Even so, the main neurological features were those of pyramidal and motor disturbance, and posterior column sense was intact. Perhaps the mechanism of injury is similar to that suggested by Kahn (1947) in cervical spondylosis. Anterior compression of the cord results in traction on the denticulate ligaments and damage to the pyramidal tract, whereas the posterior part of the cord remains relatively intact.

Paraesthesia or hyperaesthesia of the hands and fingers, which is said to be a common feature (Cone and Turner 1937), is difficult to explain, except perhaps by associated compression of the cord or nerve roots at a lower level. It is possible that the neurological picture may be caused in part by compression of the anterior spinal artery as described by Dimsdale (1954) in cases of cervical spondylosis. Such a possibility is yet another reason for early and skilful reduction in all cases with neurological manifestations.

\section{CASE REPORT}

Case 8-The following case is described to show the type of injury which is likely to be complicated by spinal cord damage. A woman of forty-five was involved in a motor accident which gave her head a severe jolt. A transient quadraplegia occurred, and she was admitted to Addenbrooke's Hospital. Recovery of movement of the legs soon took place, leaving paralysis of the upper limbs and marked hyperaesthesia of the supraclavicular nerves. Radiographs showed a fracture of the pedicles of the axis with forward displacement of the atlas (Fig. 22). Reduction was secured by skull traction (Fig. 23). Traction was continued for six weeks, during which there was gradual improvement in motor power. Some residual weakness of the right upper limb remained. She was discharged from hospital after three months, walking quite well. Three years later there was good recovery, apart from some residual pain and weakness in the right forearm and hand.

THE JOURNAL OF BONE AND JOINT SURGERY 


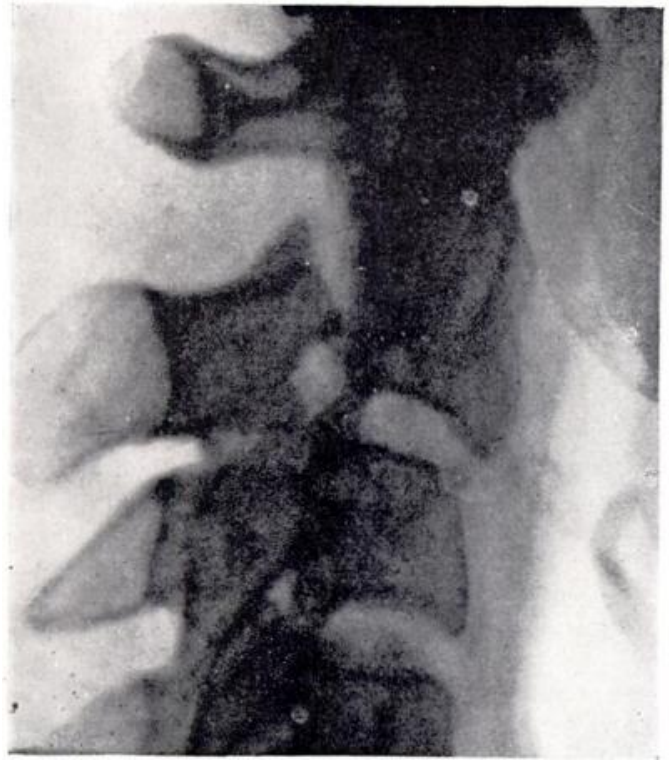

FIG. 22

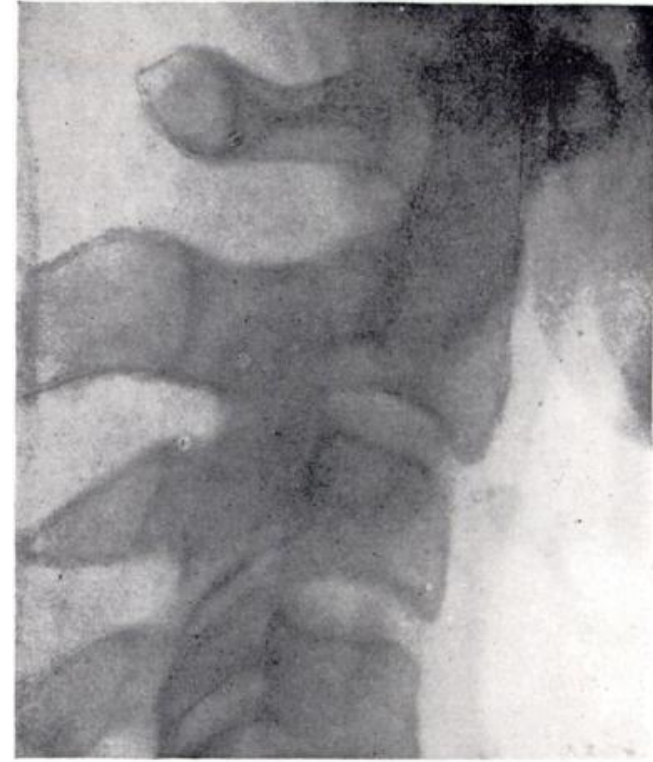

FIG. 23

Case \$. Figure 22-Fracture-dislocation of the axis with displacement of the pedicles, causing transient quadriplegia. Figure 23-After reduction.

Comment-It is interesting to compare this injury with that shown in Figure :4. This is an illustration by Wood-Jones (1913) of the ideal lesion produced in hanging. It is taken from specimens, then present in the Royal College of Surgeons, of criminals who had been hanged in the Rangoon prison. The lesion is very similar to that described in Case 8 . Sudden snapping of the pedicles of the axis has resulted in complete transection of the spinal cord. According to Teare (19:3) hanging seldom causes fracture-dislocation of the atlas and axis or fracture of the odontoid process, for the injury usually occurs at a lower level. Here there is relatively. less space in the spinal canal, so that such an injury is more likely to lead to the desired result.

\section{SUMMARY AND CONCLUSIONS}

1. Injuries to the atlas and axis may occur at any age. They are usually not fatal.

2 . In children spontaneous rotatory dislocation is the commonest type of lesion. In adults fracture of the odontoid process is more likely.

3. The spinal cord is often undamaged. In some cases complicated by cord damage the neurological disturbance is caused by an associated injury to the lower cervical spine. 4. Spinal cord damage may be immediate or delayed.

5. In cases of incomplete cord lesion there may be recovery of function after reduction of the displacement or without such reduction.

6. Diagnosis rests on the history and physical signs, and radiographic findings. Radiographs of this area require careful interpretation, and special radiographic techniques may be necessary. A normal radiograph does not necessarily exclude the possibility of atlanto-axial injury.

7. Though many patients would survive without treatment the initial discomfort and danger of complications demand

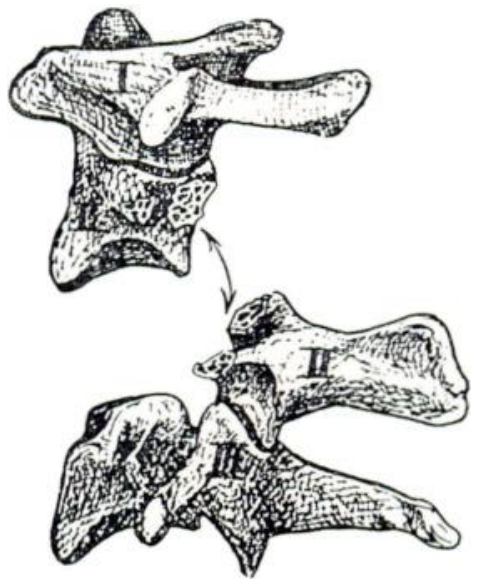

FIG. 24

The lesion present in Captain C. F. Fraser's series of judicial hangings. Separation of the arch of the axis from the body; effect of a submental knot (From Wood Jones). Compare with Figure 22.

VOL. $36 \mathrm{~B}$, NO. 3, AlGGST 1954 
that adequate protection be provided. In relatively minor injuries and in old people protection by a plaster collar may be sufficient. In some cases it is justifiable to undertake manipulation and apply a plaster. Cases with severe displacement require traction, preferably by skull calipers. Recurrent displacement, instability, and cord signs demand operative reduction and fusion. Satisfactory fusion of the atlas and axis alone is feasible, and good function is preserved. More extensive fusion of the cervical spine is seldom necessary.

I wish to thank Mr R. Weedon Butler and Mr T. J. Fairbank for permission to describe cases under their care and for their advice. Acknowledgment is also given to the Roval society of Medicine for permission to publish this report, which is based on a paper read at a meeting of the Orthopaedic Section in November 1953.

\section{REFERENCES}

Bell, C. (1830): The Nervous System of the Human Body. Embracing Papers Delivered to the Royal suciety, on the Subject of the Nerves. Appendix 127, No. 64. London: Longman, Rees, Orme, Brown and (ireen. Bersstein, R. (1903): Zur Diagnose und Prognose der Rückenmarksverletzungen. Fin Fall von Luxation mit Fraktur des Epistropheus. Deutsche Zeitschrift für Chirurgie, 70, 175.

Brav, E. A. (1936): Voluntary Dislocation of Neck. Unilateral Rotatory Dislocation of the Atlas. American Journal of Surgery, 32, 144.

Colsen, K. (1949): Atlanto-axial Fracture-Dislocation. Journal of Bone and Joint Surgery, 31-B, 345.

Cone, W., and Turner, W. G. (1937): The Treatment of Fracture-Dislocations of the Cervical Vertchrac by Skeletal Traction and Fusion. Journal of Bone and Joint Surgery, 19, 584.

Corner, E. M. (1907): Rotatory Dislocations of the Atlas. Annals of Surgery, 45, 9.

Costes (1907): Unilateral Rotatory Dislocation of the Atlas, with Fracture of th Odontoid Plocess. Quoted by Corner, E. M.: Rotary Dislocations of the Atlas. Annals of Surgery, 45, 16; and in Malgaigne, J. IF. (1855): Traité des Fractures et des Luxations, 2, 329. Paris: J. B. Baillière.

Dimsdale, H. (1954): Neurological Significance of Cervical Spondylosis. Proceedings of the Royal siciety of Medicine (Section of Physical Medicine), 47, 54.

Gibson, W. W. (1885): Dislocation of the Atlas with Fracture of the Odontoid Process. Lancet, ii, 429.

Greig, D. M. (1931): Clinical Observations on the Surgical Pathology of Bone. Edinburgh: Oliver and Boỵ. Hess, J. H., Bronstein, I. P., and Abelson, S. M. (1935): Atlanto-axial I)islocations Inassociated with Trauma and Secondary to Inflammatory Foci in the Neck. American Journal of Diseases of Children, 49, 1, 137. Jackson, H. (1950): The Diagnosis of Mlinimal Atlanto-axial Subluxation. British Journal of Radiolugy, N.S. $23,672$.

JefFerson, G. (1920): Fracture of the Atlas Vertebra. British Journal of Surgery, 7, 407.

KaHs, E. A. (1947): The Röle of the Dentate Ligaments in Spinal Cord Compression and the sindrome of Lateral Sclerosis. Journal of Neurosurgery, 4, 191.

Kahs, E. A., and Yglesias, L. (1935): Progressive Atlanto-axial 1)islocation. Journal of the American Medical Association, 105, 348.

LAMBotte, A. (1894): Un cas de fracture ancienne de l'apophyse odontoide avec luxation de l'atlas en avant. Annales de la Société Médicale d'Anvers, 56, 131.

Leriche, R., and Policard, A. (1926): Les problèmes de la physiologie normale et pathologicuue de l'os. Paris: Masson et Cie.

LounavaARA, K. I. (1949): Forward Subluxation of Atlas Following Birth Trauma. Acta Paediatrica, $37,341$. Mixter, S. J., and Osgood, R. B. (1910): Traumatic Lesions of the Atlas and Axis. Annals of Surgery, $51,193$. Pilcher, L. S. (1910) : Atlo-axoid Fracture-Dislocation. Annals of Surgery, 51, 208.

SUDECK, P. (1923): C'ber Drehungsverrenkung des Atlas. Deutsche Zeitschrift für Chirurgie, 183, 284.

Sullivan, A. W. (1949): Subluxation of the Atlanto-axial Joint. Journal of Paediatrics, 35, 451.

Swanberg, H. (1919): Anterior Dislocation of Atlas following Tonsillectomy. Journal of the American Medical Association, 72, 107.

TEARE, D. (1953): Personal communication.

Walton, G. L. (1893): A New Method of Reducing Dislocation of Cervical Vertebrae. Journal of Nervous and Mental Disease, 20,609.

Walton, G. L. (1903): Further Observations on Cervical Dislocation and its Reduction. Boston Me-lical and Surgical Journal, 149, 445.

Watson Jones, R. (1932): Spontaneous Hyperaemic Dislocation of the Atlas. P'roceedings of the Ringal Society of Medicine (Section of Orthopaedics), 25, 586.

Wittek, A. (1908): Ein Fall von Distensionsluxation im Atlanto-epistropheal Gelenke. Münchener Medizinische Wochenschrift, 55, 1,836 .

Wood-Jones, F. (1913): The Ideal Lesion Produced by Judicial Hanging. Lancet, i, 53. 